\title{
QUANTITATION OF METFORMIN IN URINE BY RP-HPLC METHOD AND ITS APPLICATION IN PHARMACOKINETICS
}

\author{
MARY REBECCA Y., SUDHA V., VIJAYAKUMAR A., HEMANTH KUMAR A. K. \\ ICMR-National Institute for Research in Tuberculosis, Chennai, India \\ Email: hemanthkumarak@nirt.res.in \\ Received: 29 Mar 2020, Revised and Accepted: 03 Mar 2021
}

\section{ABSTRACT}

Objective: To develop and validate an easy and sensitive HPLC method for quantitation of metformin in urine.

Methods: The technique involved deproteinisation of urine sample with methanol and analysis of the supernatant the usage of Zorbax 300-SCX, 4.6 $\mathrm{X} 150 \mathrm{~mm}$ ID, $5 \mu \mathrm{m}$ particle size and UV detection at a wavelength of $233 \mathrm{~nm}$.

Results: The assay was specific for metformin and linear from 1.25 to $50.0 \mu \mathrm{g} / \mathrm{ml}$. The relative standard deviation of intra-and inter-day assays was lesser than 7\%. The recovery of metformin from urine ranged from $97-103 \%$

Conclusion: An easy and sensitive HPLC approach for quantitation of metformin in urine had been developed. Due to its simplicity in sample preparation and instrumentation, this technique can be used for pharmacokinetic studies of metformin in urine samples.

Keywords: HPLC, Metformin in urine, Anti-diabetic drug, Pharmacokinetics

(C) 2021 The Authors. Published by Innovare Academic Sciences Pvt Ltd. This is an open access article under the CC BY license (https://creativecommons.org/licenses/by/4.0/) DOI: https://dx.doi.org/10.22159/ijpps.2021v13i5.41051. Journal homepage: https://innovareacademics.in/journals/index.php/ijpps.

\section{INTRODUCTION}

Metformin HCL (N, N-dimethyl imido dicarbonimidic diamide hydrochloride) (MET) is the first desire of oral hypoglycemic drug used within the remedy of non-insulin structured diabetes Mellitus (DM), through enhancing glycemic control thereby stops gluconeogenesis and glycogenolysis [1]. Being an uncrowned queen MET serves justice for the reason that FDA approved aid of United States in 1995 until date, which has paved its manner to good-sized boom in medical use [2]. Metformin is absorbed slowly submit oral administration, approximately $60 \%$ is eliminated in urine as such within $24 \mathrm{~h}$, and almost $30 \%$ of the drug dosage is non-absorbed and excreted in faeces [2]. Urine is a non-invasive sample series technique and the estimation of drug tiers in urine is simpler when in comparison to plasma and different organic body fluids that are complex [3].

Metformin is an extremely polar and small molecule, which has firstrate solubility in water and relatively poor lipid solubility. Therefore, it can be retained in reverse phase (RP) HPLC columns. Numerous methods are available to quantitate MET in urine. They encompass capillary electrophoresis with the detector of contactless conductivity [4], voltammetric approach [5], and cation alternate HPLC [6], reverse phase HPLC [7-9] and liquid chromatography mass spectrometry (LCMS) [10]. These methods had complicated sample extraction technique and improved run time.

In gasoline chromatography, chemical derivatization was applied [1113]. FT-IR (Fourier Transformation Infrared) and mass spectroscopic techniques [14] and electrochemiluminescence coupled with capillary electrophoresis [15] are other existing methodologies. However, the complexity is levelled up in these techniques, though they prove to be advantageous in terms of sensitivity.

Hence, LC is preferred mostly in biological laboratories. Although LCMS methodology had been implied for MET quantification, and techniques are efficient for selectivity and sensitivity with brief retention time, these techniques are too luxurious in growing international locations and aid poor settings.

We developed a simple HPLC method with simple sample extraction and preparation procedure using a conventional RP Zorbax SCX
Column to estimate urine MET [16]. Similar to this method, in particular to the matrix difference, we have developed and validated a specific methodology for urine MET.

\section{MATERIALS AND METHODS}

\section{Metformin}

Pure MET Hydrochloride was a kind gift from M/s Aarthi Drugs Ltd Methanol (99.80\% purity), Acetonitrile (99.9\% purity), Potassium dihydrogen phosphate $(99.5 \%$ purity), Dipotassium hydrogen orthophosphate (99\% purity) were purchased from M/s Qualigens (India) Ltd. Deionized water was processed through a water purification system (Siemens, Germany). Urine sample was obtained from normal healthy volunteers, Chennai, India.

\section{Chromatographic system}

HPLC instrumentation (Shimadzu Corporation, Kyoto, Japan) consisted of pumps (LC-20AD), photodiode array detector (SPDM20A) and automatic sampler (SIL20AC-HT) with constructed gadget controller. Lab solutions software program was used for collection and acquisition of data. The analytical column used was Zorbax 300-SCX, 4.6 X $150 \mathrm{~mm}$ ID, $5 \mu \mathrm{m}$ particle length (Agilent, USA) covered by way of a well-suited protect column. An isocratic mobile phase is a mixture of $10 \mathrm{mmol}$ phosphate buffer $(1.625 \mathrm{gm}$ of KH2PO4 and 0.3 gm of K2HPO4 in $1000 \mathrm{ml}$ of MQ Water, $\mathrm{pH} 4.8$ ) and acetonitrile in the ratio of $55: 45(\mathrm{v} / \mathrm{v})$ was used to split the analyte from the endogenous additives. Before the preparation of the mobile phase, the solvents had been degassed using a Millipore vacuum pump. The PDA detector was tuned at the wavelength of $233 \mathrm{~nm}$. The chromatogram was run for $8 \mathrm{~min}$ at $1.3 \mathrm{ml}$ flow rate per min. The column temperature turned into at $30^{\circ} \mathrm{C}$. Unknown concentrations had been derived from linear regression evaluation vs. Concentration curve. The linearity changed into established the usage of estimates of correlation coefficient (r).

\section{Preparation of standard solution}

A stock solution ( $1 \mathrm{mg} / \mathrm{ml}$ ) was prepared by dissolving MET HCL in methanol. The working standards of MET in concentrations ranging from $1.25 \mu \mathrm{g} / \mathrm{ml}$ to $50 \mu \mathrm{g} / \mathrm{ml}$ were prepared in pooled urine. 


\section{Sample preparation}

To $900 \mathrm{ul}$ of distilled water, $100 \mu \mathrm{l}$ of urine was added (1:10 dilution). To $400 \mu \mathrm{l}$ of calibration standards or test samples, $450 \mu \mathrm{l}$ of methanol was added and the contents had been vortexed vigorously for $3 \mathrm{~min}$ and centrifuged at 10,000 RPM for $10 \mathrm{~min} .75 \mu \mathrm{l}$ of the supernatant was injected into the HPLC column

\section{Method validation parameters}

Method validation were carried out as per ICH guidelines [17]

\section{Accuracy and linearity}

The accuracy and linearity of MET standards were evaluated by means of measuring a fixed of standards starting from 50 to $1.25 \mu \mathrm{g} / \mathrm{ml}$. By processing each standard in multiples for six consecutive days, the intra-day and inter-day variations were decided.

\section{Precision}

The precision of this method was calculated by analyzing different concentrations of MET in pooled urine samples in replicates on three successive days.

\section{Recovery}

On three unique events, the recuperation experiments were done. Known concentrations of MET $(2.5,10$ and $50 \mu \mathrm{g} / \mathrm{ml})$ had been made in pooled urine and were spiked with lower, median and maximum concentrations of standards. The percentage of drug restoration from urine samples was calculated by dividing the difference in MET concentrations with the aid of the estimated concentration.

\section{Specificity}

Interference from endogenous compounds was ruled out by investigating blank pooled urine samples. Interference from anti-TB drugs-rifampicin, isoniazid, ethambutol, pyrazinamide, levofloxacin, cycloserine, ethionamide, rifapentine, anti-retroviral tabletsnevirapine, efavirenz, lamivudine, stavudine, zidovudine and anti- diabetic capsules-sulphonyl ureas-glibenclamide at a concentration of $10.0 \mu \mathrm{g} / \mathrm{ml}$ were evaluated.

\section{Limit of detection (LOD) and quantitation (LOQ)}

The lower restriction of quantification became the lower maximum attention of the analyte that would be determined with proper precision and accuracy. These values have been envisioned mathematically from the standard curve equations. LOD calculations were done by the usage of the formula $3.3 \mathrm{x} \mathrm{o} / \mathrm{S}$, where $\mathrm{o}$ is the usual deviation of Y-axis intercepts and $S$ is the slope of the calibration curve.

\section{Clinical application}

We have applied this method for the estimation of urine MET in diabetes mellitus patients who were part of a pharmacokinetic study. These patients received MET $500 \mathrm{mg}$ and the urine samples collected after administration (0-8 h). Informed written consent was obtained from them prior to sample collection.

\section{RESULTS}

Under the chromatographic conditions described above, MET became well separated and seen as a discrete peak inside the representative chromatograms of extracted urine standards 50, 5.0 and $1.25 \mu \mathrm{g} / \mathrm{ml}$ and an extracted pattern from DM patient (fig. 1-5). No peak was observed at the retention time of MET (fig. 1E) in the blank urine sample. In the prevailing approach, urine MET concentrations ranging from 1.25-50 $\mathrm{\mu g} / \mathrm{ml}$ were checked for linearity. These concentrations span the range of therapeutic interest. The suggest correlation coefficient ( $r$ ), coefficient of determinants (R2), slope and intercept values have been 0.998, $0.999,0.9893,14026$ and 4321.4 , respectively (fig. 6 ). The linearity and reproducibility of the various standards used for building calibration graphs for urine MET are given (table 1). The intra-and inter-day relative standard deviation (RSD) for requirements containing $1.25-50 \mu \mathrm{g} / \mathrm{ml}$ ranged from $0.1 \%$ to $4.1 \%$ and $0.4 \%$ to $0.6 \%$ respectively. The accuracy of urine MET concentrations ranged from $96 \%$ to $107 \%$.

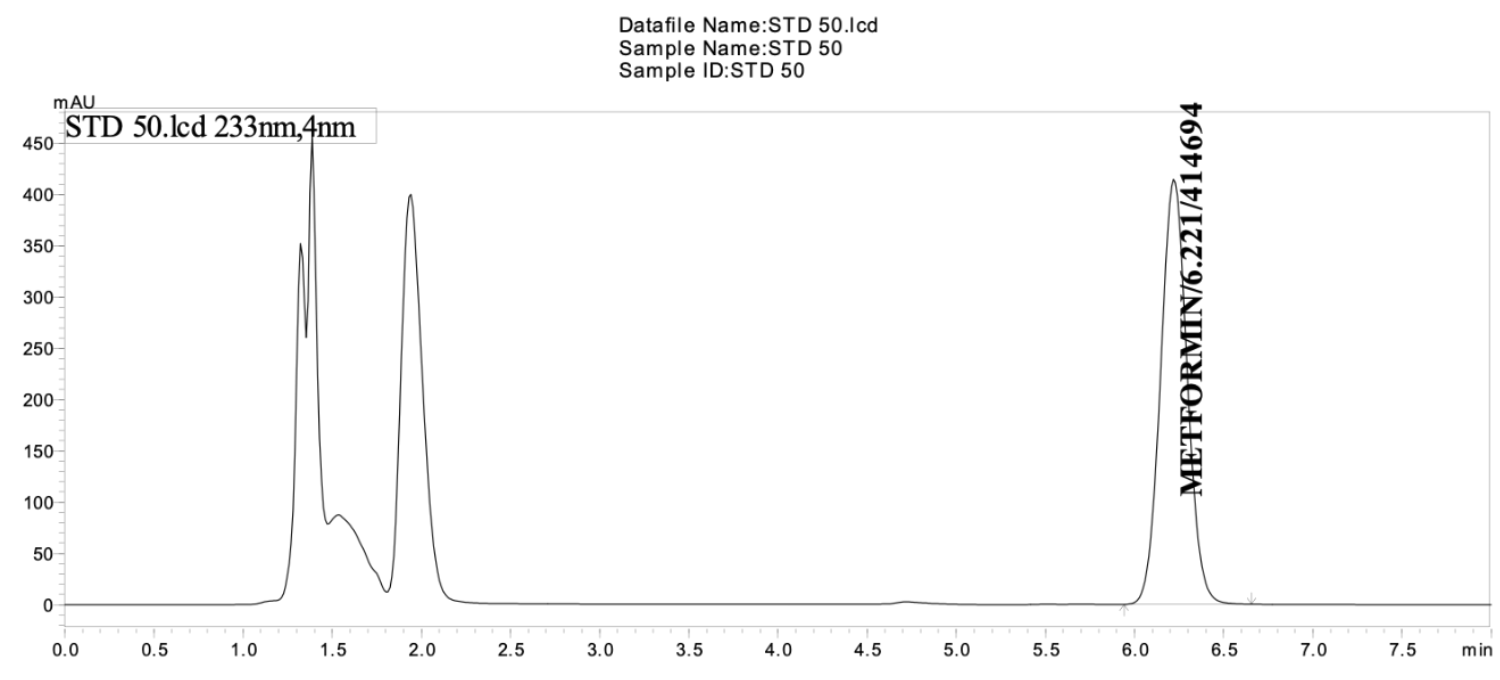

Fig. 1: Chromatogram of extracted urine metformin standard $50.0 \mu \mathrm{g} / \mathrm{ml}$

Table 1: Linearity and reproducibility of urine metformin

\begin{tabular}{lll}
\hline Standard concentration $(\boldsymbol{\mu g} / \mathbf{m l})$ & Mean peak height+SD (\%RSD) & \\
\cline { 2 - 3 } & Within day $(\mathbf{n}=\mathbf{6})$ & Between day $(\mathbf{n}=\mathbf{6})$ \\
\hline 50 & $690130.8+12575.99(1.82)$ & $709577.8+2575.7(0.36)$ \\
25 & $361542+377.2(0.1)$ & $354458.5+23489.37(6.63)$ \\
10 & $143415.3+120.01(0.08)$ & $146787.5+5221.56(3.56)$ \\
5 & $72206+1015.9(1.41)$ & $75866.3+1799.58(2.37)$ \\
2.5 & $36604.5+1512.3(4.13)$ & $35947.3+351.8(0.98)$ \\
1.25 & $17782.5+113.5(0.64)$ & $19008+1182.82(6.22)$ \\
\hline
\end{tabular}

$\mathrm{SD}=$ Standard deviation, $\mathrm{RSD}=$ Relative standard deviation, $\mathrm{n}=$ number, $\mu \mathrm{g} / \mathrm{ml}=$ microgram per milliliter 
Datafile Name:STD 5. Icd

Sample Name:STD 5

Sample ID:STD 5

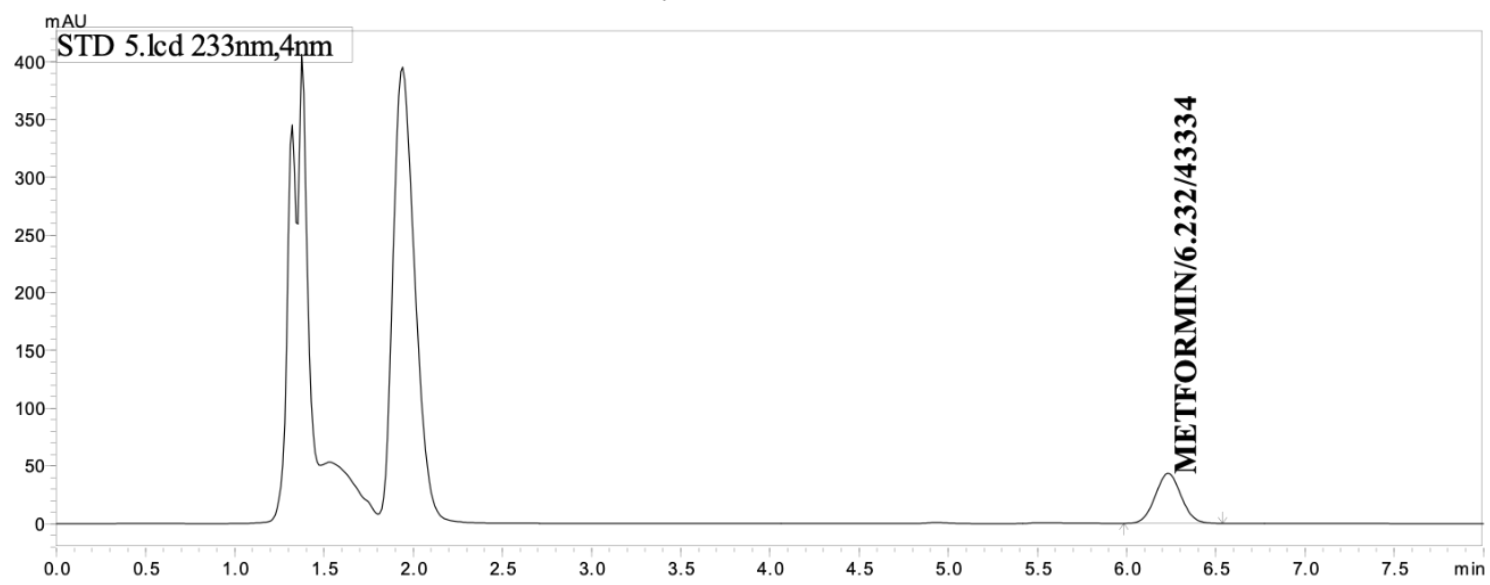

Fig. 2: Chromatogram of extracted urine metformin standard $5.0 \mu \mathrm{g} / \mathrm{ml}$

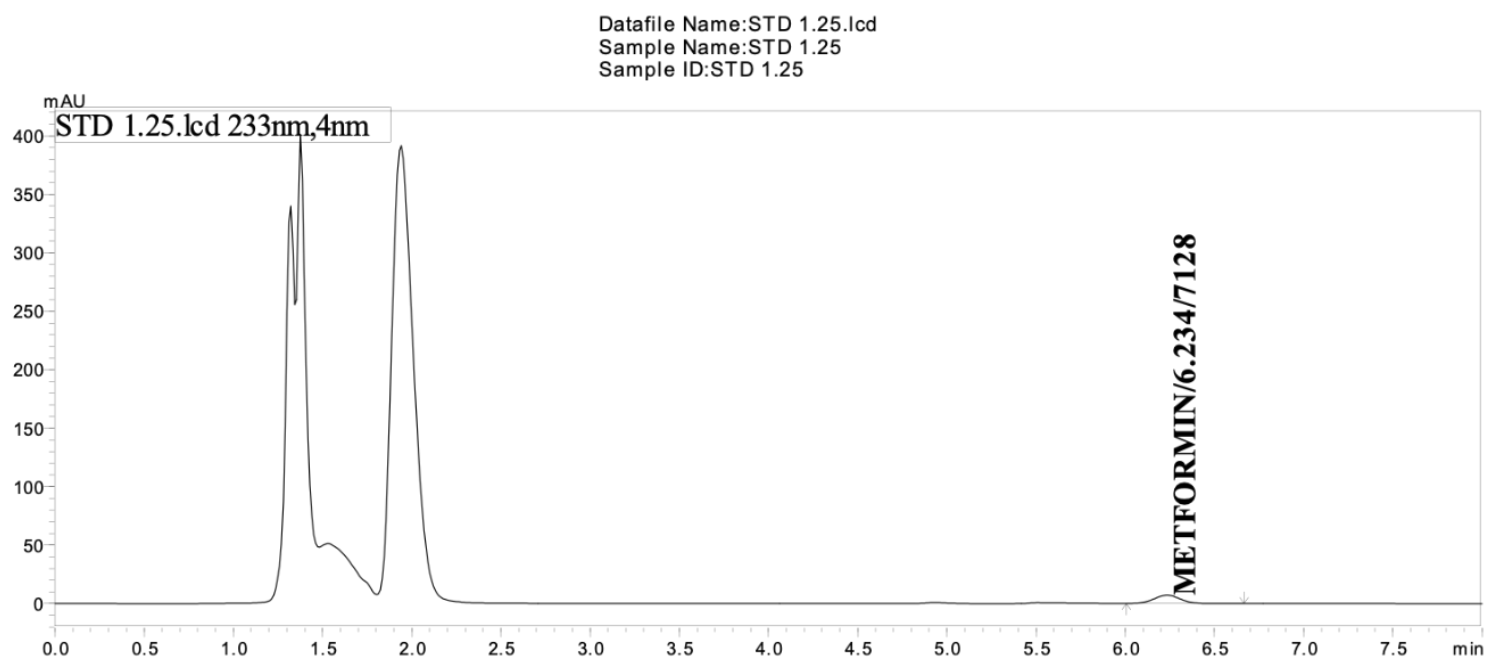

Fig. 3: Chromatogram of extracted urine metformin standard $1.25 \mu \mathrm{g} / \mathrm{ml}$

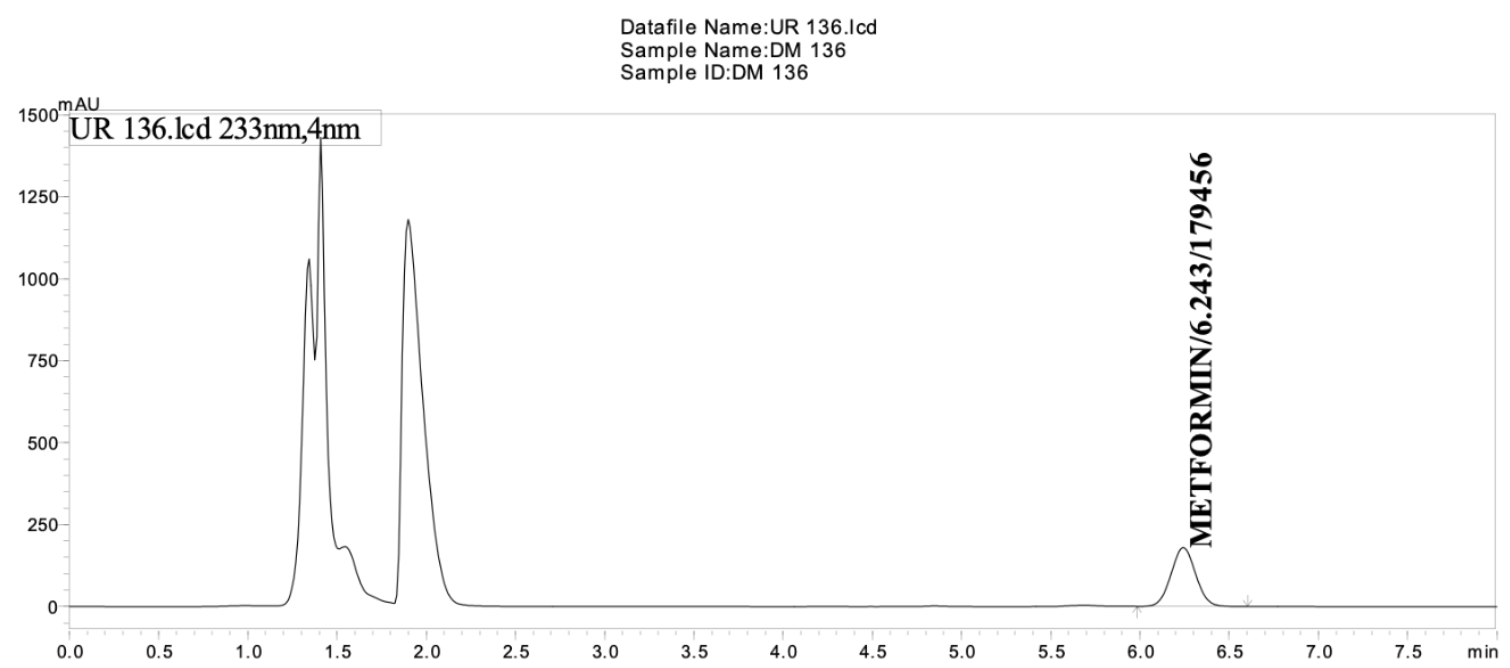

Fig. 4: Chromatogram of extracted urine metformin from a DM patient

The precision of the method was checked by analyzing three urine samples containing various concentrations of MET (table 2). The relative standard deviation (RSD) for those samples ranged from $97 \%$ to $104 \%$, respectively. The LOD and LOQ predicted mathematically from the standard curve equation were 50 and
$1.25 \mu \mathrm{g} / \mathrm{ml}$, respectively. This method reliably removed interfering substances from urine, yielding a recovery for MET that ranged from $97 \%$ to $103 \%$ (table 3). Interference from endogenous compounds changed into investigated by way of measuring blank urine samples. 


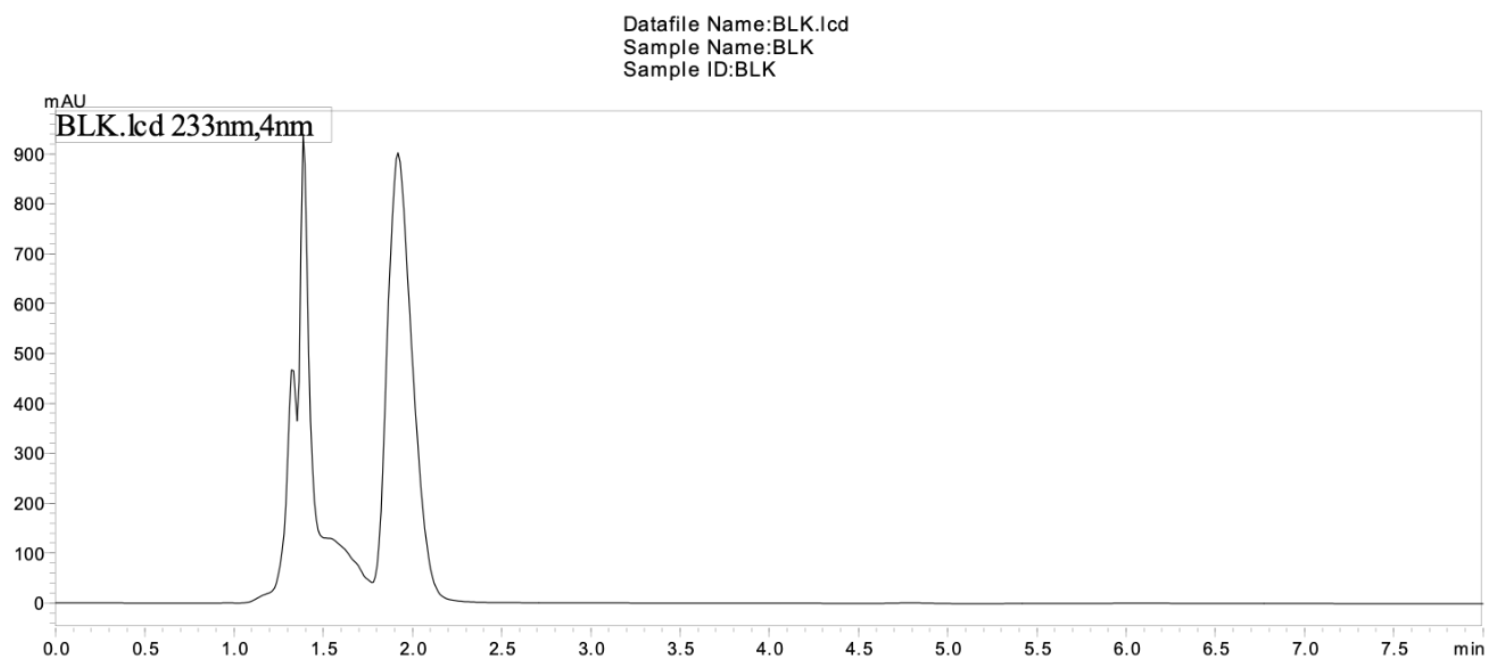

Fig. 5: Chromatogram of extracted blank urine

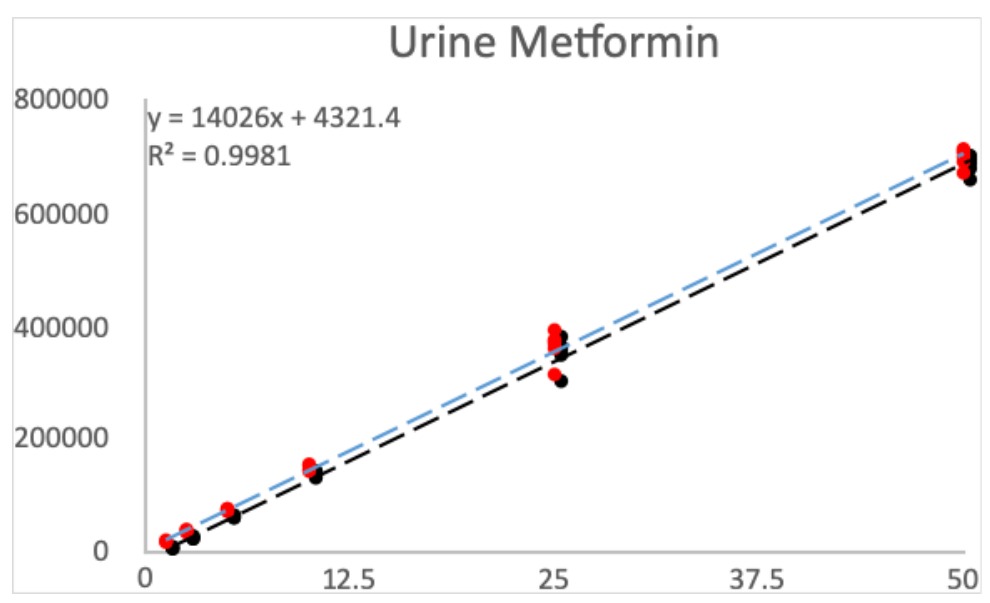

Fig. 6: Calibration curve of urine metformin

Table 2: Recovery of urine metformin

\begin{tabular}{lllll}
\hline Base & Added $(\boldsymbol{\mu g} / \mathbf{m l})$ & Actual $(\boldsymbol{\mu g} / \mathbf{m l})$ & Obtained $(\boldsymbol{\mu g} / \mathbf{m l})$ & Recovery $(\%)$ \\
\hline 50 & 12.5 & 30 & 30.91 & 103 \\
10 & 5 & 7.5 & 7.28 & 97 \\
2.5 & 1.25 & 1.875 & 1.83 & 97 \\
\hline
\end{tabular}

$\mu \mathrm{g} / \mathrm{ml}=$ microgram per milliliter

Table 3: Precision of urine metformin

\begin{tabular}{lll}
\hline Actual concentration $(\boldsymbol{\mu g} / \mathbf{m l})$ & Found concentration $(\boldsymbol{\mu g} / \mathbf{m l}) \mathbf{m e a n}+\mathbf{S D}$ & \% RSD \\
\hline 50 & $49.7+0.27$ & 99 \\
10 & $10+0.01$ & 100 \\
1.25 & $1.3+0.01$ & 104 \\
\hline
\end{tabular}

$\mathrm{SD}=$ Standard deviation, $\mathrm{RSD}=$ Relative standard deviation, $\mathrm{n}=$ number, $\mu \mathrm{g} / \mathrm{ml}=$ microgram per millilitre

Interference from certain anti-TB drugs such as Rifampicin, Rifabutin, Rifapentine, Pyrazinamide, Moxifloxacin, Lipoic acid, Levofloxacin, Ethionamide, Delamanid, Clofazimine, Bedaquiline, Cycloserine Isoniazid, anti-retroviral drugs like Efavirenz, antihypertensive drugs like Nor-verapamil, Verapamil and anti-diabetic drugs-Sulphonylureas are Glipizide, Glibenclamide, Glimmered were assayed and this method was specific for urine MET and none of these drugs showed any interference. The urine was collected from two diabetic patients was analyzed. The mean percentage of urine MET concentration in DM patients was 54\%.

\section{DISCUSSION}

Many of the present methods rent one-of-a-kind techniques for sample extraction together with the acetone precipitation approach [18], solid section extraction [19], ion-pair strong section extraction [20, 21], liquid-liquid ion-pair extraction [22-23], liquid-liquid extraction [24], protein precipitation and extraction into one step [25]. The extraction of the sample is quite complicated and time taking because of the polar nature of MET. The run time of the prevailing methods was greater than 9 min while our developed 
method has a shorter runtime of eight minutes [26]. Even the injection quantity of the sample became higher in most of the methods. Therefore, the technique developed involved simple extraction, which stays smooth, less tedious and the compound of interest become extracted in the usage of organic solvent.

We present a simple HPLC method for detection of urine MET using lesser quantity of sample. The calibration curve turned into linear in the span of $1.25-50 \mu \mathrm{g} / \mathrm{ml}(\mathrm{r} 2=0.998)$. The validation parameters are desirable for the estimation of the analyte in urine samples. We bear in mind this technique to be precise, accurate and reproducible. The developed technique discovered to be less complicated to carry out than the posted techniques for determination of MET in urine.

\section{CONCLUSION}

We have defined a simple, touchy, and specific HPLC approach for the quantitation of MET in urine. The advantageous method became tested as per Bioanalytical approach validation pointers. The technique concerned a simple pattern dilution procedure that's precise, reproducible and economic for the quantitation of MET in urine. The run time becomes $8 \mathrm{~min}$ and could be proved as better opportunity for steeply-priced liquid chromatographic-mass spectrometric technique. Urine MET method developed may be apt for pharmacokinetic and bioavailability studies.

\section{ACKNOWLEDGEMENT}

This work is part of Ph. D thesis under ICMR SRF grant and The Tamil Nadu Dr. MGR Medical University. The authors thank Mr. Dharman and Mr. Yuvaraj for helping in estimations by HPLC.

\section{AUTHORS CONTRIBUTIONS}

Dr. A. K. Hemanth Kumar: Literature search, manuscript preparation, Ms. Mary Rebecca: Method development and validation, Ms. V. Sudha: Method development and validation. Mr. A. Vijayakumar: Method validation and data preparation.

\section{FUNDING}

Nil

\section{CONFLICTS OF INTERESTS}

None

\section{REFERENCES}

1. Nelson R, Spann D, Elliott D, Brondos A, Vulliet R. Evaluation of the oral antihyperglycemic drug metformin in normal and diabetic cats. J Vet Intern Med 2004;18:18-24.

2. Scheen AJ. Clinical pharmacokinetics of metformin. Clin Pharmacokinet 1996;30:359-61.

3. Shah SA, Rathod IS, Savale SS, Patel BD. Development of a sensitive high-performance thin-layer chromatography method for estimation of ranitidine in urine and its application for bioequivalence decision for ranitidine tablet formulations. J Chromatogr B: Anal Technol Biomed Life Sci 2002;767:83-91.

4. Tůma P. Large volume sample stacking for rapid and sensitive determination of antidiabetic drug metformin in human urine and serum by capillary electrophoresis with contactless conductivity detection. J Chromatogr A 2014;1345:207-11.

5. Skrzypek S, Mirceski V, Ciesielski W, Sokołowski A, Zakrzewski R. Direct determination of metformin in urine by adsorptive catalytic square-wave voltammetry. J Pharm Biomed Anal 2007;45:275-81.

6. Charles BG, Jacobsen NW, Ravenscroft PJ. Rapid liquidchromatographic determination of metformin in plasma and urine. Clin Chem 1981;27:434-6.

7. Benzi L, Marchetti P, Cecchetti P, Navalesi R. Determination of metformin and phenformin in human plasma and urine by reversed-phase high-performance liquid chromatography. J Chromatogr 1986;375:184-9.

8. El-Gindy A, Nassar MW, El-Abasawy NM, Attia KA, Al-Shabrawi M. Optimization and validation of an RP-HPLC method for direct determination of metformin hydrochloride in human urine and in a dosage form. J AOAC Int 2010;93:1821-8.
9. Tong R, Qi X, Ding L, Song Q. Analysis of urine excretion of metformin-glipizide tablet after oral administration in healthy human. Tianjin Med J 2012;40:7-11.

10. Zhang X, Wang X, Vernikovskaya DI, Fokina VM, Nanovskaya $\mathrm{TN}$, Hankins GD, et al. Quantitative determination of metformin, glyburide and its metabolites in plasma and urine of pregnant patients by LC-MS/MS. Biomed Chromatography 2015;29:560-9.

11. Matin SB, Karam JH, Forshan PH. Simple electron capture gas chromatographic method for the determination of oral hypoglycemic biguanides in biological fluids. Anal Chem 1975;47:545-8.

12. Ross MSF. Determination of metformin in biological fluids by derivatization followed by high-performance liquid chromatography. J Chromatography 1977;133:408-11.

13. Lennard MS, Casey C, Tucker GT, Woods HF. Determination of metformin in biological samples. $\mathrm{Br} \mathrm{J}$ Clin Pharmacol 1978;6:183-5.

14. Alamgir M, Hayat A, Majidano AA, Khuhawaret MY. Spectrophotometric determination of metformin in pharmaceutical preparations, serum and urine using benzoin as a derivatizing reagent. J Chem Soc Pak 2014;36:344-9.

15. Deng B, Shi A, Kang Y, Li L. Determination of metformin hydrochloride using precolumn derivatization with acetaldehyde and capillary electrophoresis coupled with electrochemiluminescence. Luminescence 2011;26:592-7.

16. Mary Rebecca Y, Sudha V, Hemanth Kumar AK. A validated high-performance liquid chromatography method for the determination of metformin in human plasma and its application to pharmacokinetic study. J Chromatogr Sep Tech 2019;119:1-6.

17. International conference of Harmonisation (ICH). Q2(R1), Text on Validation of Analytical Procedures, Geneva, Switzerland; 2005.

18. Liu Y, Huang L, Wang J, Ding C, Xu Sh, Sun F, et al. Simultaneous determination of three diabetic drugs in urine by highperformance liquid chromatography. J Instr Anal Fenxi Ceshi Xuebao 2011;30:293-7.

19. Nielsen F, Christensen Mette MH, Brøsen K. Quantitation of metformin in human plasma and urine by hydrophilic interaction liquid chromatography and application to a pharmacokinetic study. Ther Drug Monitor 2014;36:211-7.

20. Tahara K, Yonemoto A, Yoshiyama Y, Nakamura T, Aizawa M. Determination of antihyperglycemic biguanides in serum and urine using an ion-pair solid-phase extraction technique followed by HPLC-UV on a pentafluorophenylpropyl column and on an octadecyl column. Biomed Chromatography 2006;20:1200-5.

21. El-Kumar Mean EI, Yourself RM, Allah. A high-performance thin-layer chromatographic assay of metformin in urine using ion-pair solid-phase extraction: application for bioavailability and bioequivalence study of new micro beads controlled release formulation. J Planar Chromatogr Mod TLC 2014;27:377-84.

22. Garrett ER, Tsar J, Hindering PH. Application of ion-pair methods to drug extraction from biological fluids. II. Quantitative determination of biguanides in biological fluids and comparison of protein binding estimates. J Pharm Sci 1972;61:1411-8.

23. Keal J, Simonyi A. Rapid and sensitive high-performance liquid chromatographic assay for metformin in plasma and urine using ion-pair extraction techniques. Chromatography B Biomed Appl 1986;378:503-8.

24. Garb RQ, Pedal RS, Brocks DR. Determination of metformin in human plasma a urine by high-performance liquid chromatography using small sample volume and conventional octadecyl silage column. Pharm Sci 2010;13:486-94.

25. Lennard MS, Casey C, Tucker GT, Woods HF. Determination of metformin in biological samples. $\mathrm{Br} \mathrm{J}$ Clin Pharmacol 1978;6:183-5.

26. Eva Trojan, Leonard Deda, Gezim Bocari. Ion pair HPLC method for the quantification of metformin in human urine. J Appl Bioanal 2016;2:16-24. 